\title{
LA ÉTICA DE LOS DERECHOS HUMANOS
}

EDUARDO C. B. BITTAR

Livre-Docente y Doctor;

Profesor Asociado del Departamiento de Filosofía y Teoria General del Derecho de la Facultad de Derecho de la Universidade de São Paulo (USP);

Profesor y Pesquisador del Programa de Mestrado en Derechos Humanos del UniFIEO;

Presidente de la Associación Nacional de Direitos Humanos (ANDHEP - NEV-USP);

Membro pesquisador del Núcleo de Estudios da Violência (NEVUSP).

andhep@gmail.com

Artigo submetido em espanhol 


\section{RÉSUMÉ}

This article touchs the problem of the ethics of humain rights, and discuss all the questions about the principle of the discurs in the domain of the Constitution of the State under the lights of the humain dignity.

\section{RESUMO}

En face de la tarea de interpretar el discurso constitucional y extraer la importancia para la afirmación de ciudadanía de un Estado, se presenta una mirada posible, una visón metodológica, para la averiguación del sentido y de la importancia del principio de la dignidad de la persona humana para la hermenéutica constitucional.

Key-words: ethics - hermeneutics - dignity - humain rights.

Palabras-Llave: ciudadanía - ética - hermenéutica constitucional - dignidad de la persona humana - derechos humanos. 


\section{LA NUEVA ÉTICA CONSTITUCIONAL: EL SIGNIFICADO HISTÓRICO DE LA CONSTITUCIÓN FEDERAL DE 1988}

La Constitución Federal de 1988 provocó cambios significativos, que necesariamente afectan factores culturales, mecanismos institucionales y prácticas sociopolíticas enraizadas dentro del ordenamiento jurídico brasileño. En este sentido, el texto de la Constitución constituye un innovador legado legislativo, que va a ser administrado por la comunidad de intérpretes, cuya responsabilidad es dar concretude y efectividad a las conquistas construidas bajo el bastión del regreso de la democracia.

A partir de ella, se abre un nuevo panorama jurídico, sin ninguna duda identificado con las más hodiernas concepciones de derecho, especialmente en lo que dice respecto a los derechos fundamentales. La propia sociedad promulga la Constitución, recibe los efectos de esta promulgación, vive el clima de modificaciones por ella instituido, en la exacta medida del preparo para que estas pequeñas revoluciones conceptuales y políticas ocurran.

Entonces, cuando se discute la temática de la presencia de prescripciones éticas en el texto de la Constitución Federal Brasileña de 1988, hay que se considerar el avanzo jurídico-democrático perpetrado por la introducción de este texto en el ordenamiento jurídico nacional. Esto porque, en gran parte, los conceptos que fueron introducidos por el legislador constituyente de 1988 causaron grandes revoluciones en las diversas áreas en que el Derecho se proyecta.

Esto significa decir que los ámbitos señoriales del derecho patrio tuvieron que se moldar y se adaptar a las condiciones valorativas y conceptuales previstas con la promulgación de la actual Constitución, que tiene entre sus principios fundamentales, los objetivos y los fundamentos de la Republica Federativa de Brasil las dicciones presentadas por los artículos $1^{\circ}$ y $3^{\circ}$ del texto constitucional.

Pero, se debe percibir, sobretodo, que estas modificaciones no son de interés exclusivo de la ciencia jurídica, y menos de los juristas patrios. Las modificaciones introducidas causaron profunda ruptura de valores, que afecta directamente la sociedad y sus demandas jurídicas, con el sistema jurídico anteriormente organizado bajo los cánones diversos de los que hoy son considerados relevantes. Entonces, se esta delante de una Constitución apodada de ciudadana y no sin motivo, pues porque este texto representa una formulación jurídica que abraza los deseos de la sociedad y se coloca al servicio de la ciudadanía, como instrumento de la misma, en el sentido de la realización de los fines sociales deseados por la sociedad brasileña.

En este sentido, para abrazar los valores sociales más emergentes y relevantes, el legislador constituyente tuvo de se atener a las profundas modificaciones por las que viene pasando la nación brasileña, para producir un texto constitucional que corresponda a las necesidades inmediatas y futuras de la sociedad brasileña, poniendo la ciudadanía y la dignidad humana adelante de cualesquier otras exigencias lógico formales, técnico jurídicas o políticas potestativas.

De hecho, la Constitución inaugura un nuevo conjunto de preocupaciones éticas. Esto porque, en verdad, la orden jurídica constitucional visa más que todo alcanzar la plenitud del convivido social pacifico. De esta forma, las normas jurídicas son predispuestas a produciren efectos prácticos sobre el comportamiento y la conducta de las personas, de las sociedades, de las organizaciones, de las corporaciones, de las cooperativas, de las instituciones, de los sindicatos, de los órganos gubernamentales... en el sentido de efectivamente causaren repercusiones sobre la ética de la populación, la moral social y la conciencia de una sociedad. 
Esta es la declaración de las intenciones que viven entorno de la prisión normativa primordial del ordenamiento jurídico brasileño. He ahí también, la idea de constituyente, para que sirva de ingrediente pala calentar la hermética y para incrementar la principiologia constitucional.

\section{EL COMPROMISO PRIMERO DE LA CONSTITUCIÓN CON LA CIUDADANÍA: LA GARANTÍA DEL DERECHO DE TENER OPCIÓN ÉTICA}

Cuando se habla en ética, necesariamente se piensa en la relación entre comportamiento e intención del individuo, así que ethos es la revelación de su hábito de acción. Toda acción comporta, necesariamente su aspecto subjetivo (posibilidad de comportamiento por la conjuntura de los datos externos que condicionan el actuar). La función del Derecho, dentro de la lógica de la construcción de relaciones socio humanas concordante con el espirito del convivio pacifico y racional, es dispensar elementos que beneficien la independencia ética de los individuos y reequilibren las desarmonías comportamentales resultantes del entrechoque de albedríos (Kant).

También el derecho de tener libertad de decidir éticamente pasa por la cuestión del equilibrio entre inclinaciones internas del individuo y asedios advenidos de los estímulos externos. Son los desafíos existenciales de la producción de decisiones éticamente contratadas no pueden ser despreciadas en el momento en que los conflictos y los imperativos de acción empiecen a hervir, exigiendo una toma de posición.

Las aflicciones del humano son el reflejo característico de la dimensión ético reflexiva. Por lo tanto, de poca relevancia son las tradicionales ideas de una dimensión ética desencajada de la perspectiva vivida de los individuos dimensionados en condiciones históricas de producción de decisiones éticas. Por eso es que se debe preguntar, ¿cuando si discute el estado actual de la ética, como va el ser humano? Datos oficiales apuntan que, del contingente poblacional mundial, mitad de la población vive con menos de 2 dólares al día y que 1 mil millones de personas viven con 1 dólar al día. En Brasil, se estima que 6.000.000 de trabajadores no tienen remuneración. En 27 de abril de 2004, el periódico Folha de São Paulo revelaba que el desempleo alcanza 12,8\% de la población económicamente activa de las seis regiones metropolitanas más grandes del Brasil, de acuerdo con datos de IBGE, lo que significa 2,7 millones de parados. ¿No se trata de una sociedad bulímica, para usar una expresión de Claude Lévi-Strauss, que, después de invitar todos al consumo, los rechaza como residuos del proceso económico?

Lo que está ocurriendo no es difícil evaluar. Sin querer dar crédito al determinismo, la conclusión solo puede ser una, la de que se está cazando el derecho de libertad ética, las acorralando en el vacuo de la miseria.

\section{ANÁLISIS DE LA EXPRESIÓN “DIGNIDAD DE LA PERSONA HUMANA”}

Si el texto jurídico es el punto de partida de la interpretación jurídica, es siempre a partir del texto (y no de la intención del legislador) que el intérprete jurídico inicia su recorrido en dirección de la búsqueda del sentido jurídico. ${ }^{1}$ Lo que hay, entonces, es que el locus de la interpretación es el texto, y esto en la medida en que el texto es un imperativo en la circulación de los fenómenos jurídicos. Texto es más que texto escrito y menos que referente discusivo, hay textos donde hay una determinada complejidad de señales, una especie de conjunción de los signos que se proponen a significar además de lo que individualmente significan. ${ }^{2}$

Texto es más que texto escrito y menos que referente discusivo, hay textos donde hay una especie de complejidad signica, cierta conjunción de los signos que se proponen a significar además de lo 
que individualmente significan. ${ }^{3}$

Es así que cualquier expresión constitucional (“dignidad de la persona humana”) es ya un texto de una comunidad de intérpretes, debiéndose destacar que la interpretación no se separa de un sentido oculto de los términos jurídicos (como si existiera un "secreto" del legislador escondido en la pequeña "Caja de Pandora" del texto jurídico), pero crea, a partir de determinada condiciones, el sentido pragmático posible a dar cuerpo a una determinada practica social, dentro de objetivos socialmente relevantes. El texto es, por lo tanto, punto de partida para que el sujeto de la interpretación de él se valga para determinada categoría de sentido.

En este sentido, interpretar no es solo ato atributo de vida dentro de la dinâmica de construcción del Derecho, como también interpretar presupone una determinada actitud metodológica delate de aquello que se llama de Derecho y delante de aquello que se identifica como una Constitución.

La cuestión de la mirada es, por lo tanto, determinante de la forma como se interpreta una norma jurídica dentro del sistema, especialmente cuando esta norma tiene posición de jerarquía y supremacía, si destacada de las demás sólo por su presencia dentro del texto constitucional.

Retomando un artículo adagio hermenéutico, se puede decir que no hay expresiones vanas dentro de una Constitución (¿o sería la expresión "dignidad de la persona humana?). Si esto es verdad, entonces la tarea de discusión del sentido de la expresión dignidad de la persona humana debe revelas una preocupación sobre los términos en que se manifiesta la Constitución. Así, el estudio hermenéutico demanda una determinada actitud hermenéutica, cuya misión no deja de ser: 1. revelar la lógica - o fío conductos - del texto constitucional, en la medida en que todo el texto constitucional hace opciones ideológicas y es marcado por valores que son electos como valores fin; 2 . detectar cuales son los principios que organizan la estructura del pensar dogmático constitucional; 3. operacionalizar la hermenéutica para que sirva de instrumento para que la Constitución Federal pueda alcanzar sus fines sociales.

Y, cuando se parte para estudiar las tácticas tradicionales de la hermenéutica jurídica, encuentrase desde pronto lo que debe ser combatido en las vigas envejecidas de la hermenéutica jurídica tradicional, para que se pueda afirmar lo que se pretende defender como premisa de la evaluación de la expresión mencionada, a partir de una concepción centrada en una nueva hermenéutica: ${ }^{4}$

En el lugar del privilegio de la interpretación judicial, del intérprete auténtico y exclusivo (kelseniano) porque detentor del poder de decisión, aspecto fundamental de una sociedad cerrada, la interpretación de la sociedad abierta; 5

En el lugar de la interpretación como manifestación de poder del Estado por encima de la sociedad, bajo la influencia de la teoría democrática, hay que se hablar en la construcción de una sociedad abierta de los interpretes de la Constitución (Die offene Gesellschaft der Verfassungsinterpreten); ${ }^{6}$ en el lugar de la supremacía del legislador, la prevalencia de las lecturas que se encuentran en las versiones de los interpretes y usuarios del sistema normativo; en el lugar del jurisprivatismo, centrado en la noción de propiedad y exclusivismo de uso, la presentación del pluralismo político y la garantía de la diversidad; en el lugar de la interpretación auténtica (kelseniana), la presentación de los agentes sociales como diálogo permanente de la propia sociedad sobre si misma; en el lugar de la función inactiva de ciudadanía popular por el voto, la ampliación de la competencia de la ciudadanía para proyectarse sobre el suelo hermenéutico, vinculando su opinión al proceso de crecimiento de la concepción de Constitución que se tiene y que si quiere ${ }^{7}$ en el lugar de la función cognitiva de la jurisdicción, que impide la practica judicial, la función creativa de la jurisdicción para la recreación permanente del sistema jurídico; en el lugar de la interpretación civilista, centrada en el Código, la presentación de una visión del Derecho desarrollada a partir de la interpretación constitucionalista 
centrada en la Carta Fundamental; en el lugar de la visión de interpretación como alcance de la verdad (in claris cessat interpretatio), la discusión sobre la interpretación a partir de juegos lingüísticos y contextos sociales; en el lugar del método técnico dedutivista de acceso al sentido de las normas, el desarrollo de una metodología tópico problemática de discusión y producción de justicia concreta.

Abstraer la circunstacialidad de la producción de un texto es, sin duda, la causa de serios errores en sed de interpretación. De ahí la necesidad de, al visitar el sentido de la expresión "dignidad de la persona humana" tenerse que recoger a una evaluación de sus diversos aspectos, desde los histórico filosóficos, hasta los relacionados a su topografía en el texto constitucional. Es de esta tarea que se reviste la perspectiva del trabajo ahora empezada.

\section{SENTIDO HISTÓRICO-FILOSÓFICO}

En un análisis histórico filosófica, ${ }^{8}$ la idea de "dignidad de la persona humana" es la convergencia de diversas doctrinas y concepciones de mundo que vienen siendo construidas desde larga data en la cultura occidental. La noción no esta ausente del pensamiento griego, pues de manifestar en la concepción cosmológica de responsabilidad ética de los estoicos, y gana profundo aliento con el desarrollo del pensamiento cristiano, especialmente considerado la cultura de la igualdad de todos delante de la creación.

Pero, son los modernos que darán una configuración más precisa para el tema. La cuestión de la dignidad de la persona humana es declarada presente en los debates modernos con la Oratio de Hominis Dignitate, del siglo XV (1486), de autoría de Giovanni Pico Della Mirandolla (Disurso sobre a dignidade do homem, 2001, p. 49), cuando se percibe la necesidad de unir la visión del antropocentrismo ascendente con la visión de la autonomía del ser humano a partir de su naturaleza: Leí en los escritos de los Árabes, venerando padres, que cuestionado Abdala Sarraceno cual seria, a sus ojos, el espectáculo más maravilloso en este escenario de mundo, tenía contestado que nada veía de más admirable que el hombre. Con esta sentencia concuerda aquella famosa frase de Hermes: Grande milagro, ó Asclépio, es el hombre" ("Legi, Patres colendissimi, in Arabum monumentis, interrogatum Abdalam Sarracenum, quid in hac quasi mundana ascaena admirandum maxime spectaretur, nihil spectari homine admirabilius repondisse. Cui sententiae illud Mercurii aadstipulatur: magnum, o Asclepi, miraculum est homo").

Entre los modernos, será Kant quien habrá de profundar esta discusión, discutiéndola a partir de la idea de igualdad, poniéndola en el centro de la discusión a respecto de la naturaleza humana racional. En su pensamiento, por lo tanto, la dignidad (würde) viene de la naturaleza humana racional, en la medida que significa dominación y capacidad de autoatribución de reglas de comportamiento. ${ }^{9}$

De hecho, la dignidad tiene que ver con esta capacidad de ser autónomo, en la medida en que actúa la razón legisladora y moral. Si hay un mundo de los fines absolutos (esfera del incondicional, del no relativizable, del inapreciable), en contraposición al mundo de los fines relativos (esfera del precio, del cambio, del útil, del variable), la definición humana recurre de su condición invariable e no valorable, en la medida en que nadie vale más que nadie, a la inversa de las cosas in comercio. El uso de la ley moral es un uso de la razón legisladora en favor de la humanidad como fin, o sea contraria a la idea que el hombre se torne instrumento o medio para su realización de fines personales o individualistas (imperativo categórico). En la expresión de su imperativo: “Ahora yo afirmo, el hombre, en general, todo ser racional, existe como fin en si mismo, no solo como medio para cualquier uso de esta o de aquella voluntad" (Kant, Fundamentos da metafísica dos costumes, trad., p. 78).

Kant es el portal del iluminismo, el punto de apoyo y de partida para la parte más grande de los pensadores modernos (Hegel, Schelling,...), y, por lo tanto, referencial teórico de la modernidad. En 
este sentido, la noción de dignidad constante de su pensamiento adentra definitivamente al universo de las discusiones filosóficas modernas, y, por esta vía, acaba encontrandose dentro de la perspectiva de los valores base de afirmación de la propia modernidad jurídica. El derecho será afectado por esta concepción de dignidad así como será afectado por la idea de um proyecto cosmopolita de paz perpetua.

El tema de la "dignidad de la persona humana", por lo tanto, viene mejor explicitado a partir de la modernidad, y es como tal que se entrega a la historia contemporánea para tornarse un principio que es la base de la cultura de los derechos. Sin embargo, el foso de la indignidad, o sea, el conocimiento de la máxima capacidad humana de destrucción de la dignidad (utilizándose de todos los artificios de razón, como tortura, tecnología, ciencia, urbanismo, limpieza social, etc.), con la ayuda de la razón, solo surgiría con la experiencia de la Segunda Guerra Mundial, marco histórico existencial de un cambio de concepciones que habría de re orientar las políticas internacionales ( a partir de la noción de DIDH fundada en el postguerra, con el Tribunal de Nuremberg, la formación de la ONU y la creación de la Declaración Universal de los Derechos Humanos) bien como las propias concepciones filosóficas del mundo. Es esto que hace con que la noción de dignidad parezca contestar, en un momento postmoderno de reflexiones, al anuncio de una identidad, o de un término común, entre las diversas ideologías y líneas de pensamiento contemporáneas.

No se trata, por lo tanto, de um tema creado en la postmodernidad (a partir de la desilusión con la razón, en el postguerra), tratase de una discusión filosófica bien torneada con la modernidad, sin embargo, torna objeto de aflicción internacional, de conmoción mundial y de derecho positivo internacional solamente en el siglo XX, en el postguerra, con la Declaración Universal de los Derechos Humanos, de 1948, donde se lee: $1^{\circ}$. Considerando de la Declaración de 1948: "Considerando que el reconocimiento de la dignidad inherente a todos los miembros de la familia humana y de sus derechos iguales e inalienables es el fundamento de la libertad, de la justicia y de la paz en el mundo"; e: art. 1 ${ }^{\circ}$. "Todas las personas nacen libres e iguales en dignidad y derechos". Para que la expresión adentrase a la legislación positiva, fueron necesarios diversos estorbos y diversos sacrificios a definieren las condiciones para su inscripción en medio a la cultura afirmativa de los derechos humanos. ${ }^{10}$ Desde entonces, se torna criterio de parametrización del sentido del propio Derecho.

\section{SENTIDO TOPOGRÁFICO DE LA EXPRESIÓN EN EL DERECHO POSITI- VO BRASILEÑO}

Su entrada en la cultura del derecho nacional se da a partir del texto de la Constitución Federal de 1988, en un período de redemocratización y, por lo tanto, de creciente afinación de la cultura del derecho nacional a la cultura del derecho internacional de los derechos humanos (D.I.D.H.) que viene desarrollandose desde su fundación con la Declaración de 1948 como reacción a las atrocidades del período nazista y a los demás efectos de la Segunda Guerra Mundial, que provocó la muerte de millones de seres humanos.

Desde entonces, la idea de 'dignidad de la persona humana' pasa a ser criterio para la determinación y evaluación de la legitimidad de la política, de la justicia del derecho, de las decisiones de relevancia para la humanidad. En su nombre se torno posible quebrar siglos de funcionamiento del concepto westfaliano de la soberanía, para que fuera posible la relativización de la idea de soberanía en nombre de la protección de individuos perseguidos por la opresión del poder. Es cierto que, imediatamente, tratavase del efecto de una humanidad cansada de los desvaríos provocados por el grand confronto mundial, que, en reacción, grabó este valor en el centro de la arquitetura de los sistemas jurídicos contemporáneos. Tornase, desde entonces, consenso para el censo común, para la ciencia, para la religión, para la filosofía, adentrando al texto de las declaraciones internacionales 
(como el "Pacto internacional de los derechos económicos, sociales y culturales", en su $2^{\circ}$. considerando: "Reconociendo que estos derechos resultan de la dignidad inherente a la persona humana" y el "Pacto de São José de la Costa Rica", de 1969, en su art. 11, parágrafo 1'.: "Toda persona tiene derecho al respecto de su honra y al reconocimiento de su dignidad"), de las Constituciones actuales ye de las legislaciones nacionales. ${ }^{11}$

En la Constitución Federal de 1988, aparece explícitamente en el art. 1º, inciso III ("La Republica Federativa del Brasil, formada por la unión indisoluble de los Estados y Municipios y del Distrito Federal, se constituí en Estado Democrático de Derecho y tiene como fundamentos: III - la dignidad de la persona humana"), e en los artículos 230 ("La familia, la sociedad y el Estado tienen el deber de amparar los viejos, asegurando su participación en la comunidad, defendiendo su dignidad y bienestar y le garantizando el derecho a la vida"), 226 ("La familia, base de la sociedad, tiene especial protección del Estado. $\S 7^{\circ}$ - Fundado en los principios de la dignidad de la persona humana y de la paternidad responsable, el planeamiento familiar es libre decisión del casal, competiendo al Estado propiciar recursos educacionales y científicos para el ejercicio de este derecho, vedada cualquier forma coercitiva por parte de instituciones oficiales o privadas") y art. 227 ("Es deber de la familia, de la sociedad y del Estado asegurar al niño y al joven, con absoluta prioridad, el derecho a la vida, a la salud, a la comida, a la educación, al descanso, a la profesionalización, a la cultura, a la dignidad, al respecto, a la libertad y a la convivencia familiar y comunitaria, además de ponerles a salvo de toda forma de abandono, discriminación, exploración, violencia, crueldad y opresión"), y en la legislación infraconstitución se modelará de modo explícito también en el Estatuto de los niños e del adolescente, en su art. 15 ("Los niños y los adolescentes tienen derecho a la libertad, al respecto y a la dignidad como personas humanas en proceso de desarrollo y como sujetos de derechos civiles, humanos y sociales garantizados en la Constitución y en las leyes").

Se debe entender, por lo tanto, que la Constitución Federal de 1988 posee un gran potencial transformador de la sociedad brasileña. La Constitución erigió valores guía electos para la arquitectura del sistema jurídico, entre los cuales se encuentra el principio de la dignidad de la persona humana, inscrito en el art. $1^{\circ}$., inciso III. Es en este sentido que se debe proyectar como un texto de formateación fundamental de la cultura de los derechos humanos dentro de una sociedad pluralista. Su defensa es, a un solo tiempo, la defensa de las propias condiciones de construcción de una sociedad que es capaz de estipular valores comunes y construirlos dentro de un sistema razonable de medidas y parámetros para la arquitectura del convivo social.

La tradición constitucional constumbra neutralizar el potencial transformador de estas reglas al describirlas como "normas de eficacia programática", o simplemente traducidas en el uso corriente de el lenguaje jurídico como "Normas programáticas". El peligro de este tipo de concepción es el de anestesiar la perspectiva de sentido introducida por la Constitución, tornando grande parte de sus normas inocuas, porque no son inmediatamente utilizables, para toda una comunidad de interpretes y desfrutadotes de las conquistas constitucionales introducidas por la innovación de 1988.

Todavía que se considere que la norma que identifica en el principio de la "dignidad de la persona humana" una regla fundamental del funcionamiento de la República Federativa del Brasil sea diferente de las otras normas y reglas constitucionales, lo más simples consentimiento del sentido del principio para un futuro longincuo reduce por completo la posibilidad de se exigir de los interpretes auténticos del sistema jurídico nacional su aplicación. De ahí, la necesidad de se hacer una distinción: políticamente, tiene función de programa, y, por eso, su sentido es inagotable - mientras fuera vigente la Constitución, se estará buscando dar dignidad a las personas por la actuación del Estado; jurídicamente, el art. $1^{\circ}$., inciso III da CF88 no necesita de nada más para se tornar norma de pleno valor para el texto constitucional. Como esta norma no limita un derecho, y mucho confiere al sistema una enunciación vinculativa del desfruto de ningún derecho, tiene función estrictamente 
estrictamente directivo principiológica para el texto constitucional, de modo que no puede ser interpretada como una norma que presenta un derecho o un deber.

Por lo tanto, como norma que enuncia solo um principio, como valor guía para el sistema, es norma de plena eficacia, porque inscrita en el texto constitucional y que no necesita de ninguna otra que le confiera sentido más preciso. Ningún principio podrá ser restricto o mucho menos definido por legislación infraconstitucional, porque no es tarea del legislador limitar principios o mucho menos definir el sentido de las normas.

Así, la norma constitucional contenida en el $1^{\circ}$., inciso III, es norma constitucional y posee sentido pleno, vinculativo, por lo tanto, de la interpretación constitucional. Intérpretes constitucionales deben tener en esta norma una regla matriz de lectura de la lógica común a toda la Constitución Federal de 1988, y, por eso, están vinculados a esta regla como valor fuente, en la expresión de Miguel Reale, para la dicción de todos los derechos.

Esta norma puede, por lo tanto, no ser vinculativa de la producción político material de sus efectos concretos inmediatos (porque las metas políticas son siempre inagotables, en búsqueda programática de desarrollo de una sociedad), pero es norma no apartable de la lógica constitucional, prisión axiológica para la garantía de la homogeneidad del texto constitucional, cuyos capítulos desdoblanse a partir de la lógica fundacional del art. $1^{\circ}$ como un todo, en especial, del III. Su importancia se debe, por lo tanto, a la inversión producida por la Constitución de 1988, al enunciar los derechos fundamentales antes de las atribuciones del Estado, y al presentar sus principios fundamentales ante todo; el principio de "dignidad de la persona humana" viene topográficamente localizado en la apertura del texto constitucional y esto no debe ser, en hipótesis alguna, ignorado del punto de vista de una hermenéutica constitucional (como si las normas del "Orden económica" o del "orden tributaria" valieran independientemente de la validad de los principios que inauguran el texto constitucional).

Es, por lo tanto, norma semánticamente vinculativa de la decisión judicial, de las acciones administrativas de Estado, a ser leída e interpretada al lado de las demás previsiones constitucionales, e infraconstitucionales, que le dan la característica más específica para la discusión de cada materia. Se lee este principio al lado de la norma de derecho positivo que se quiere aplicar al caso concreto, y es de la oscilación y del equilibrio del principio con la norma positiva que surge la conjugación suficiente para la evaluación del caso concreto. La no instrumentalización humana (ética de medios) es lo que guía el orden constitucional, y, mientras el orden constitucional de abrigo al arbitrio, al abuso, a la dominación, a la barbarie, decisiones deberán enfrentar el embate del precepto de la dignidad de la persona humana con los demás preceptos que lo hacen obstáculo para el cumplimiento de esta meta.

\section{SIGNIFICACIÓN E IMPRECISIÓN DE LA EXPRESIÓN: CONTRAPOSICIÓN DE DOS VISIONES}

La expresión es claramente una de estas locuciones abierta, aporetica, que remeten a una experiencia de fondo problemático, y con esto, a una dimensión poros del lenguaje jurídico, que, en principio, debe conferir "acierto", "seguridad" y "objetividad". Entonces, se deparar con la abertura de una expresión que graba un principio como este parece representar una amenaza a la cohesión y a la precisión del Derecho! De ahí, se espanta la expresión por su inutilidad como se espanta el indefinible para dentro del foso de las experiencias "no-registradas" por el conocimiento científico.

Ora, ni todo aquello que se refiere a experiencias fundamentales de los seres humanos, a pesar de reconocidamente ser consideradas fundamentales, remete necesariamente a definiciones precisas. Por ejemplo, el termo "justicia" sigue siendo un termino vago, pero ni por eso dispensable del 
filosófica (todavía que sean múltiplas las corrientes a les definieren el sentido), y mucho menos discartable de la conjunción de las relaciones sociales (todavía que las reivindicaciones por justicias sean las más variables posibles).

Aun que para los sépticos la imprecisión de la expresión "dignidad de la persona humana" representa un desafío insoportable para la razón, solamente superable por su ignorancia, redundando de ahí la inoperacionalidad de la noción (por la dificultad de conceptuación), por se tratar de un concepto abierto, plurívoco, se debe superar esta sensación de "calleja", de "encrucijada" sin dirección, por una otra. De hecho, se debe contritamente, entender que "la dignidad de la persona humana" es, antes de todo, una expresión que sirve como: 1.) fundamento del Derecho y Del propio Estado; 2.) norte de las acciones gubernamentales; 3.) télos de las políticas sociales; 4.) principio hermenéutico, especialmente por su topografía textual, para todos los derechos humanos y los demás derechos del texto constitucional (justicia social, política legislativa; moralidad administrativa; política económica y tributaria; políticas penitenciarias; etc.); 5.) directriz para la legislación infraconstitucional; 6.) base para la aplicación judicial de los derechos; 7.) punto de partida para la lectura del ordenamiento jurídico; 8.) Foco de dispersión con lo cual se debe construir la protección de la persona humana; 9.) núcleo de sentido de las prácticas jurídicas; 10.) fundamento para la creación de de instrumentos de protección de la persona humana.

Se trata de una especie de resumen de las ambiciones constitucionales, soma ideológica, o matriz principiológica que cumple la "pretensión de corrección del derecho", en la dirección de Alexy. Esta completa expresión, semánticamente cargada de diversas implicaciones, contiene en si el resumen, la soma ideológica, la matriz principiológica... de todos los capítulos, sea del texto constitucional, sea de toda y cualquier propuesta contenida en el ordenamiento jurídico. ${ }^{12}$ Es ella la meta social de cualquier ordenamiento que vise alcanzar y fornecer, por medio de las estructuras jurídico-político-sociales, la plena satisfacción de las necesidades físicas, morales, psíquicas y espirituales de la persona humana. Sin embargo, la "dignidad humana" atendida significa no propiamente la satisfacción de querencias individuales (o idiosincrasias), pero de un minimun exigible socialmente, capaz, por sus recursos, medios y técnicas, de alcanzar justicia social. En esta línea, lo que se externa es una preocupación con la transformación de discursos en acciones, de letra de ley en políticas publicas, de normas pragmáticas en programas de transformación de la sociedad, desde las sus más intrínsecas limitaciones, en el sentido de la afirmación práctica y de la realización de la abrengéncia de la expresión dignidad de persona humana, normalmente tenida como mero expediente retórico del legislador constitucional. ${ }^{13}$

Aun así, vale decir que, a pesar de la imprecisión de la expresión, ella debe servir como norte de les acciones gubernamentales y de las acciones sociales, en el sentido de planificación de la persona humana en el convivio social. La expresión dignidad de la persona humana, ${ }^{14}$ por lo tanto, deja de representar mero concepto abierto de la Constitución y gana un sentido como télos de les políticas sociales, limite mismo que permite diferir el justo Del injusto, el aceptable del inaceptable, el legitimo del ilegitimo. Se registra, con so, que su importancia se debe al hecho de se encontrar topográficamente localizada en el principio de la Constitución, el que denuncia sobre prevaléncia hermenéutica para la discusión exegética de sus demás dispositivos.

La dignidad de la persona humana es una expresión de amplio alcance, que reúne en su escopo todo el espectro de los derechos humanos (que son tratados en el ámbito privado como derechos de la personalidad), que se difunde por diversas dimensiones dogmático-jurídicas, alcanzando: 1.) relaciones de consumo; 2.) prestación de servicios esenciales por el Estado; 3.) cumplimento de políticas públicas; 4.) atendimento de necesidades sociales; 5.) construcción de la justicia social; 6.) base de las tomadas de decisión en política legislativa; 7.) base de la idea de moralidad administrativa y exigibilidad de conducta de los gobernantes; 8.) cierne de las políticas económicas 
y de distribución de recursos (justicia distributiva); 9.) base para el desarrollo de acciones tendentes al desarrollo de acciones educacionales, urbanas y rurales, penitenciarias, etc. ¿Cómo decir que se trata de una expresión non sense? ¿Cómo aferir en su amplitud un vacío?

De su abertura es que se nutre, por lo tanto, la posibilidad de, por la exigencia lingüística y de los juegos de acción históricamente determinados, surgir la definición in casu del digno y del indigno. No se sabe decir, precisamente, lo que es "decencia", y ni por eso no sabemos identificar las situaciones de decencia o vileza. ${ }^{15}$ Lo mismo ocurre con las situaciones en que se tenga que identificar el digno y el indigno: ${ }^{16}$ un homicidio es un atentado a la dignidad humana; la miseria es un atentado a la dignidad humana; la marginalidad es un atentado a la dignidad humana; la dependencia físicopsíquica es un atentado a la dignidad humana; la violencia doméstica es un atentado a la dignidad humana. La violencia urbana es un atentado a la dignidad humana; la discriminación es un atentado a la dignidad humana; el desvío de finalidades en las actividades públicas un atentado a la dignidad humana; las hipótesis generadoras de danos morales son un atentado a la dignidad humana; la violación de imagen un atentado a la dignidad humana. ${ }^{17}$

La persona humana es de verdad el locus de esta indeterminación, especialmente considerado que la historia de la humanidad todavía no se enceró, y que la humanidad todavía anda de gatitas sobre la construcción de las experiencias que marcan sus principios y valores centrales.

\section{SENTIDO PRINCIPIOLÓGICO DE LA EXPRESIÓN: LA ÉTICA DE LOS DERECHOS HUMANOS}

Una ética de los derechos humanos discurre directamente del principio de la dignidad de la persona humana. De hecho, este principio equivale a un lugar-común para el abrigo de todas las generaciones de derechos humanos, de los de primera hasta los de tercera generación. La justicia no puede ser pensada isoladamente, sin el principio de la dignidad humana, así como el poder no puede ser exigido a pesar de la dignidad humana. ${ }^{18}$ De verdad, todos los demás principios y valores que orientan la creación de los derechos nacional e internacional, se curvan delante de esta identidad común o a este minimum de los pueblos. La propia Declaración de 1948 le confiere tal posición de superioridad ante los demás principios y valores. ${ }^{19}$ Como referencia motivante de la cultura de los derechos humanos, además de fundamental, este principio tiene valía universal. ${ }^{20}$ Solo quiere, a pesar de su universalidad, su construcción no es fruto de una deducción de la razón, pero un constructor histórico, y, como tal, que deberá ser sometido a la ampliación Del uso de su sentido a contextos históricos los más variados, en los juegos de realidad y de lenguaje. ${ }^{21}$ Desproveída de universalismos, la palabra dignidad (dignitas - latín) ${ }^{22}$ parece corresponder a un importante foco, e, por lo tanto, a un importante centro convergente de ideas y preocupaciones sociales, en medio a les dispersiones pos modernas, donde el destaque dado reitera la importancia de la conquista histórica de los derechos fundamentales. ${ }^{23}$ Pensar en la perspectiva que se amplía para el siglo XXI es pensar en el hecho de que la dignidad pasa a recuperar su valor, su sentido, se recomponiendo para hacer parte Del discurso jurídico Del milenio que irrumpe ya marcado por innumeras violaciones a los derechos fundamentales de la persona humana.

De hecho, la apurada observación Del momento permite decir que la persona humana es puesta nuevamente en foco, y su valoración recupera foros de decencia social mínima, ampliando la temática de la dignidad de la persona humana, como télos del propio ordenamiento jurídico o mismo como criterio de cualquier idea o forma de justicia. ${ }^{24}$ No que esto sea una realidad practica efectiva, pero que se este a percibir esta cambio de preocupaciones de los propios juristas y estudiosos de cuestiones jurídicas. $^{25}$

Fueron necesarias violaciones, diversas experiencias de indignidad, diversas prácticas de exploración

Hendu 1 (1): julho, 2010 
exploración de la condición humana, para que la propia noción de dignidad surgiera un pozo más claro a los ojos de pensamiento contemporáneo. "El sufrimiento como matriz de la comprensión del mundo e de los hombres, según la tarea luminosa de sabedora griega, vino profundar la afirmación histórica de los derechos humanos", como afirma Comparato. ${ }^{26}$ Parece que la personalidad recupera el espacio perdido en los desvíanos de la erosión de la ética de les ultimas décadas Del siglo XX, y Del largo proceso que dio origen al nihilismo, al tecnicismo, al ceticismo y a la relativiza absoluta de todos los valores. En fin, en pocas palabras parece la Idea de personalidad recuperar su sentido pleno, rellenando el hueco de las experiencias sépticas y materialistas del tecnologismo del siglo $\mathrm{XX}$, e invadiendo las diversas líneas de pensamiento ocupadas con los desvaríos de la historia contemporánea.

Los discursos que se afinan y deputas en la aurora del siglo XXI se aprimoran en proteger, conocer, desvendar, en una palabra, dignificar la personalidad humana, no en actitud de idolatría, pero en actitud de auto-conocimiento, al estilo socrático (gnoûth autos, gr., "te conoce a ti mismo"), verdadero caminos para la comprensión del yo, atajo para el entendimiento del otro, de sus querencias y derechos, bien como de la sociedad, de su mecánica y finalidad. Esta situación sintomática de comunión y afinidad de los discursos (de la ciencia, de la religión, Del censo común, de la arte, de la filosofía, Del esoterismo, de les dogmáticas jurídicas...) corresponde a un estado de espirito de humanidad, cansada que se encuentra de los modelos que originaron el esgotamiento de los valores del final del siglo XX, sedienta de cambios. Es posible entrever cambios, cuando el desarrollo de las naciones y de los pueblos se da en la misma medida de la evolución y expansión de la conciencia ética: "Hay una base firme de esperanza sobre la cual asentar los esfuerzos en vista de protección de la dignidad humana: es el fortalecimiento general de la conciencia ética" (Comparato, A afirmação histórica dos direitos humanos, 1999, p. 411).

\section{LA “DIGNIDAD DE LA PERSONA HUMANA" EN UNA SOCIEDAD ABIERTA Y PLURALISTA}

Si la mínima moralia de los derechos humanos resulta de la idea de dignidad, esta debe ser lastre para la construcción de una sociedad abierta y pluralista, principiándose por la necesidad de superación de las dicotomías clásicas (competencia constitucional y legitimidad procesal, Estado y sociedad civil, derecho público y interés privado etc.) que dividen y atraviesan el escenario jurídico, en dirección a la construcción de una concepción según la cual la hermenéutica se encuentra al servicio de los intereses preponderantes del propio pueblo. Una sociedad abierta y pluralista presupone, ante todo, que sus valores no estén estancados, y mucho menos controlados de modo centralizado solamente por la comprensión y por la visión de mundo de autoridades de Estado.

El valor de la "dignidad de la persona humana" dentro de la cultura de una sociedad abierta y pluralista presupone no solamente la preponderancia de esta visión sobre os otros valores (aquél que podría ser dicho la regla común de todos los derechos humanos), pero sobretodo que sus valores, consagrados incluso a través de normas jurídicas, siendo una de ellas y la de mayor importancia la Constitución (y su función especular de la sociedad pluralista) ${ }^{27}$, estén en permanente proceso de cambio inter subjetivo, que pertenezcan al nível de diálogo común inter comunicativo (de un actuaren-comun al rededor de principios), que comparezcan al espacio público para su crítica y discusión, para que estén de acuerdo con una ética del actuar comunicativo (Habermas).

Esto es lo que exige que una sociedad pluralista tenga sus valores, especialmente cuando dignificados por la positivación jurídica en la condición de principios (como el caso del principio de la "dignidad de la persona humana") o normas de carácter constitucional (como es el caso de la desapropiación por interés social para fines de la reforma agraria, del art. 184 CF 88), especialmente considerada la situación de su consagración como derechos fundamentales (como es el caso 
del derecho a la tutela jurisdiccional de los derechos, art. $5^{\circ}$., inc. XXXV, CF 88), expuestos no solamente al debate público, de acuerdo con una ética del actuar comunicativo (Habermas), pero sobretodo abierto a la amplia interpretación por parte de los agentes sociales. No es solamente la interpretación auténtica, en el sentido kelseniano, aquella que definirá el sentido de las normas del ordenamiento, pero un aglomerado de juegos continuos de lenguaje (Wittgenstein), que hará con que el permanente cambio de estas interpretaciones transforme la Constitución no solamente en un documento formal, de Estado (legislador) para Estado (juez), pero un documento real, de Estado (legislador) para Sociedad (agentes sociales) y de Sociedad (agentes sociales) para Estado (juez).

En estas condiciones, se puede considerar posible la superación del Estado de Derecho en dirección a un Estado Constitucional (Häberle) ${ }^{28}$ A pesar de las expresiones normalmente recibieren un tratamiento equivalente, no raro siendo utilizadas como sinónimos ${ }^{29}{ }^{29}$ posible distinguirlas identificando en el Estado de Derecho un tipo específico de Estado, acuñado en la lógica del legalismo burgués, sustentado por el naciente naturalismo iluminista (Hobbes, Locke, Rousseau, Kant), inspirado en el ideario liberal centrado el las ideas de propiedad e libertad, desarrollado bajo la cultura novecentista del positivismo jurídico y de la ciencia dogmática (Rechtswissenchaft), habría de encontrar sus primeras modificaciones cuando de la ascensión de los debates de carácter social y reivindicativo que acabaran por producir la idea de un Estado Social o de Bienestar Social. Su obsoletismo contemporáneo no solamente es notorio, como es sistemáticamente necesario que su superación histórica se procese en la identificación de nuevos paradigmas de regencia del sistema jurídico; en la transición paradigmática, se debe considerar la importancia de un pasaje de lo legalismo (Estado de Derecho) al constitucionalismo (Estado Constitucional). ${ }^{30}$ Una cultura que implica este proceso de superación de las condiciones de limitación auto impuesta a partir de la propia dialéctica de las ideas en la historia, es lo que marca el creciente mecanismo de revisión de la cultura político jurídica prevalecente para que se fijen las bases de desarollo de un Estado Constitucional (Pérez Luño). ${ }^{31}$

Dentro de esa línea de raciocinio, caminar en dirección al Estado Constitucional significa ampliar la función política del judiciario, es decir, abrazar las críticas al Estado de Derechos, cuales sean, el rigorismo deductivista de la legalidad y la limitación del positivismo jurídico, para constituirlo no como el único intérprete del ordenamiento jurídico y ni mismo como el intérprete que parte del Código de Derecho Privado para comprender el sistema jurídico. ${ }^{2}$ Se trata de comprender que la función política del Poder Judiciario es la que traslada su función de aplicador del sistema codificado (juez como bouche de la loi), en dirección a la politización del sentido de las metas sociales, de las ambiciones axiológicas, de las finalidades políticas elegidas, contenidas en la dinámica de una Constitución de carácter pluralista y democrático.

\section{NOTAS}

${ }^{1}$ La opción hermenéutica ahora iniciada congrega elementos de una hermenéutica textual (Ricoeur) con una semiótica pragmática (Ferraz Jr. e F. Rastier). La resultante es una pragmática textual, que habrá de construirse en etapas en esta disertación. Es necesario resaltar con Umberto Eco que: "Entonces se afirma (pensemos con inflexiones diferentes, en la linea que une el último Barthes, el último Derrida, Kristeva), que la significación pasa solamente a través de los textos, que los textos son el lugar donde el sentido se produce y produz (práctica significante) y que, en este tejido textual, se pueden dejar aflorar nuevamente los signos del diccionario, mientras equivalencias codificadas, desde que haya el enrijecimiento y la muerte del sentido" (Eco, Semiótica e filosofia da linguagem, 1991, p. 31). Y, aún más, con la misma opinión, pero con una posición lingüística de los fenómenos da interpretación y del texto, se acompanha Ross: "Toda interpretación del derecho legislado comienza com un texto, esto es, una fórmula lingüística escrita" (Sobre el derecho y la justicia, $3^{\mathrm{a}}$ edição, 1974, p. 108). A respeito da relação hermenêutica/ semiótica, consulte-se Ricoeur, Entre herméneutique et semiotique, in Nouveaux Actes Sémiotiques, 1990, ps. 03/ 19. 
${ }^{3}$ Tendo em vista esta noção de complexidade que está a rechear a idéia de texto, pode-se dizer do texto que se trata de um composto, a um só tempo: semântico (sentido sígnico), sintático (interação sígnica), pragmático (uso sígnico), estético (apresentação sígnica).

${ }^{4}$ Teniendo en vista esta noción de complejidad que está a llenar la idea del texto, se puede decir del texto que tratase de un compuesto, a solo um tiempo: semántico (sentido sígnico), sintático (interacción sígnica), pragmático (uso sígnico), estético (apresentación sígnica).

${ }^{5}$ Cf. Callejón, M. L. B., Interpretación de la Constitución y ordenamiento jurídico, Tecnos, 1997, p. 23-48. 4"La teoría de interpretación constitucional estuvo muy vinculada a un modelo de interpretación de una "sociedad cerrada". Ella reduce, todavía, su âmbito de investigación, en la medida que se concentra, primariamente, en la interpretación constitucional de los jueces y en los procedimientos formalizados" (Häberle, P., Hermenêutica Constitucional. A sociedade aberta dos intérpretes da constituição: Contribuição para a interpretação pluralista e "procedimental" da constituição, Sergio Antonio Fabris, 2002, p. 12).

6"En ese sentido, se permite colocar la cuestión sobre los participantes del proceso de la interpretación: de uma sociedad cerrada de los interpretes de la Constitución para una interpretación constitucional por la y para una sociedad abierta (von der geschlossenen Gesellschaft der Verfassungsintepreten zur Verfassungsinterpretation durch und fur die offene Gesellschaft)." (Häberle, P., Hermenêutica Constitucional. A sociedade aberta dos intérpretes da constituição: Contribuição para a interpretação pluralista e "procedimental" da constituição, Sergio Antonio Fabris, 2002, p. 12-13).

7 “" "Pueblo", no es solo un referencial cuantitativo que se manifesta en el dia de la elección y que, como tal, dae legitimidad democrática al proceso de decisión. Pueblo es también un elemento pluralista para la interpretación que se hace presente de forma legitimadora en el proceso constitucional: como partido político, como opinión científica, como grupo de interés, como ciudadano. Su competéncia objetiva para la interpretación constitucional es un derecho de ciudadanía en el sentido del art. 33 de la Ley Fundamental (NT 8). De esa forma, los Derechos Fundamentales son parte de la base de legitimación democrática para la interpretación abierta tanto no que se refiere a lo resultado, cuanto en lo que se dice respecto al circulo de participantes (Beteiligtenkreis). En la democracia liberal, el ciudadano es interprete de la Constitución!" (Häberle, P., Hermenêutica Constitucional. A sociedade aberta dos intérpretes da constituição: Contribuição para a interpretação pluralista e "procedimental" da constituição, Sergio Antonio Fabris, 2002, p. 37).

${ }^{8}$ Cf. Comparato, F. K., A firmação histórica dos direitos humanos, Saraiva, 1999, p. 44.

${ }^{9}$ Canto-Sperber, M. (org.), Dicionário de ética e filosofia moral, Unisinos, 2003, verbete dignidad.

${ }^{10}$ Cf. Comparato, F. K., A firmação histórica dos direitos humanos, Saraiva, 1999, p. 44.

${ }^{11}$ Se pueden enunciar las demás normas de carácter internacional que abrigan el principio: "A) A nivel continental: Convención (Europea) de salvaguardia de los derechos del hombre y de las libertades individuales (Roma,4 de noviembre de 1951); Carta Social Europea (Turín, 18 de octubre de 1961); Convención Americana de Derechos Humano (22 de noviembre de 1969); Carta Africana de los Derechos del Hombre y de los Pueblos (1982); Declaración Americana de los Derechos y de Deberes del Hombre (Bogotá, 1948); Declaración Islámica Universal de los Derechos del Hombre (París, 1982); B) Convenciones internacionales: Convención para la prevención y la sanción del genocidio (1948); Convención sobre los derechos políticos de la mujer (1953); Convención complementaria sobre abolición de la esclavitud, tráfico de esclavos y practicas similares a la esclavitud (1956); Convención relativa e la eliminación de toda forma de discriminación racial (1965); Convención de la UNESCO relativa a la lucha contra las discriminaciones en la esfera de la enseñaza (1960); Convención no. 87 de la OIT relativa a la libertad de asociación y a la protección del derecho de organización sindical (1951); Convención no. 105 de la OIT relativa de la abolición del trabajo forzoso (1957); Convención no. 111 de la OIT relativa a la no discriminación en materia de empleo y ocupación (1958)" (Pascual, R. M., Ética de los Derechos Humanos, Tecnos, 2000, p. 57). 
${ }^{12}$ Para que se pueda aquilatar la abrangência Del sentido de la expresión, se debe afirmar que la dignidad de la persona humana puede alcanzar diversas perspectivas: um homicídio es um atentado a la dignidad humana; la miséria es um atentado a la dignidad humana; la marginalidad es um atentado a la dignidad humana; la dependência físico-psiquica es um atentado a la dignidad humana; la violência doméstica es um atentado a la dignidad humana; la violência urbana es um atentado a la dignidad humana; la corrupción es um atentado a la dignidad humana; el desvío de finalidad en las actividades publicas es um atentado a la dignidad humana las hipótesis generadoras de danos morales son un atentado a la dignidad humana. 